\title{
A major role for intestinal epithelial nucleotide oligomerization domain 1 (NOD1) in eliciting host bactericidal immune responses to Campylobacter jejuni
}

\author{
Matthias Zilbauer, ${ }^{1}$ Nick Dorrell, ${ }^{2 \star}$ Abdi Elmi, ${ }^{2}$ \\ Keith J. Lindley, ${ }^{3}$ Stephanie Schüller, ${ }^{4}$ \\ Hannah E. Jones, ${ }^{1}$ Nigel J. Klein, ${ }^{1}$ Gabriel Núňez, ${ }^{5}$ \\ Brendan W. Wren ${ }^{2}$ and Mona Bajaj-Elliott ${ }^{1 *}$ \\ ${ }^{1}$ Infectious Diseases and Microbiology Unit, Institute of \\ Child Health, 30 Guilford St, London WC1N 1EH, UK. \\ ${ }^{2}$ Department of Infectious and Tropical Diseases, Keppel \\ Street, London School of Hygiene and Tropical \\ Medicine, London WC1E 7HT, UK. \\ ${ }^{3}$ Department of Gastroenterology, Institute of Child \\ Health and Great Ormond Street Hospital, 30 Guilford \\ St, London WC1N 1EH, UK. \\ ${ }^{4}$ Centre for Paediatric Gastroenterology, Royal Free and \\ University College Medical School, Rowland Hill St, \\ London NW3 2PF, UK. \\ ${ }^{5}$ Department of Pathology and Comprehensive Cancer \\ Centre, University of Michigan Medical School, Ann \\ Arbor, MI, USA.
}

\section{Summary}

Campylobacter jejuni is the foremost cause of bacterial-induced diarrhoeal disease worldwide. Although it is well established that $C$. jejuni infection of intestinal epithelia triggers host innate immune responses, the mechanism(s) involved remain poorly defined. Innate immunity can be initiated by families of structurally related pattern-recognition receptors (PRRs) that recognize specific microbial signature motifs. Here, we demonstrated maximal induction of epithelial innate responses during infection with live C. jejuni cells. In contrast when intestinal epithelial cells (IECs) were exposed to paraformaldehyde-fixed bacteria, host responses were minimal and a marked reduction in the number of intracellular bacteria was noted in parallel. These findings suggested a role for intracellular host-C. jejuni interactions in eliciting early innate immunity. We therefore investigated the

Received 15 March, 2007; revised 24 April, 2007; accepted 25 April, 2007. *For correspondence. E-mail nick.dorrell@Ishtm.ac.uk; Tel. (+44) 207927 2838; Fax (+44) 207637 4314; E-mail M.Bajaj-Elliott@ich.ucl.ac.uk; Tel. $\quad(+44) 207905$ 2215; $\quad$ Fax (+44) 2078138494. potential involvement of a family of intracellular, cytoplasmic PRRs, the nucleotide-binding oligomerization domain (NOD) proteins in $C$. jejuni recognition. We identified NOD1, but not NOD2, as a major PRR for C. jejuni in IEC. We also found that targeting intestinal epithelial NOD1 with small interfering RNA resulted in an increase in number of intracellular $C$. jejuni, thus highlighting a critical role for NOD1-mediated antimicrobial defence mechanism(s) in combating this infection at the gastrointestinal mucosal surface.

\section{Introduction}

Campylobacter jejuni is the most prevalent cause of bacterial diarrhoea worldwide and the leading cause of infectious enterocolitis in the Western world (Mead et al., 1999; Allos, 2001). C. jejuni colonizes and survives as a commensal in the gastrointestinal (Gl) tract of many birds and other animals (Park, 2002), however, in humans as few as 500 bacteria can cause symptomatic disease (Black et al., 1988). Undercooked poultry, cross-contamination of other foods with raw poultry, contaminated water and unpasteurized dairy products are known sources of human infection (Humphrey, 2006). Clinical symptoms typically manifest with cramping abdominal pain, vomiting and fever followed by mild, watery or inflammatory and bloody diarrhoea (Lambert et al., 1979; Black et al., 1988; Lamps et al., 2006). Although C. jejuni-mediated diarrhoea is the 'classical' clinical manifestation in majority of individuals, in some people further complications can arise. These include Guillain-Barré Syndrome (GBS) a paralysis occurring 2-3 weeks post infection (Goodyear et al., 1999), and longer term sequelae such as reactive arthritis (Peterson, 1994; Leirisalo-Repo, 2005).

Despite the serious health burden caused by this bacterium, our current understanding of $C$. jejuni-mediated disease pathogenesis remains limited. The self-limiting nature of $C$. jejuni-mediated diarrhoea clearly indicates that effective immune defence mechanism(s) are operative in healthy individuals allowing for successful, rapid clearance of infection. As the first site of bacterial contact, the intestinal epithelial cell (IEC) plays a critical role in initiating host defence to enteropathogens (Islam et al., 
2001; Eckmann, 2005; Sansonetti and Di Santo, 2007). Our own previous work has indicated that endogenous antimicrobials such as $\beta$-defensins may be directly involved in controlling infection as these peptides are induced by $C$. jejuni and exhibit potent bactericidal activity against the organism (Zilbauer et al., 2005). Studies have also demonstrated secretion of the potent neutrophil chemoattractant interleukin-8 (IL-8) by IECs in response to wild-type (WT) C. jejuni (Hickey et al., 1999; 2000; Watson and Galan, 2005; Johanesen and Dwinell, 2006). Both bacterial structural [e.g. cytolethal distending toxin (CDT)] components and active processes such as adhesion/invasion and de novo protein synthesis have been implicated in eliciting epithelial innate immune responses (Hickey etal., 2000; Mellits et al., 2002; Watson and Galan, 2005). Despite advances in our understanding of the role and contribution of bacterial factors implicated in C. jejuni-mediated epithelial responses, at present our knowledge remains rudimentary as to how the host senses and initiates an effective immune response to the presence of the bacterium.

Innate recognition of microorganisms is an ancient mode of defence shared throughout the plant and animal kingdom (Ganz, 2003; Akira, 2006). A triad of patternrecognition receptor (PRR) families are now known to be involved in recognizing invariant structures or pathogenassociated molecular patterns (PAMPs) on microorganisms (Inohara et al., 2005; Takeda and Akira, 2005; Franchi et al., 2006; Werts et al., 2006). The most extensively studied PRRs are the Toll-like receptors (TLRs), which comprise evolutionarily conserved transmembrane proteins that recognize bacterial structural components such as lipopolysacchride (LPS), flagellin, lipoproteins, lipoteichoic acid and unmethylated CpGDNA (Janeway and Medzhitov, 2002; Akira, 2006). Recent evidence suggests that Campylobacter flagellin is a poor ligand for IEC TLR5 playing no significant role in bacterial-mediated host epithelial responses (Watson and Galan, 2005). The potential role and contribution of other epithelial TLRs to $C$. jejuni recognition at present is unclear.

The well recognized 'invasive' nature of $C$. jejuni drew our attention to elucidate the contribution, if any, of the second PRR family, i.e. the cytoplasmic nucleotidebinding oligomerization domain (NOD) proteins to IEC innate immunity (Inohara et al., 2005). NOD1 (encoded by the caspase-recruitment domain 4 gene; CARD4) and NOD2 (encoded by CARD15) recognize components of peptidoglycans (PGNs), ubiquitous constituents of bacterial cell walls (Inohara and Núňez, 2003; Inohara et al., 2005; Franchi et al., 2006). The minimal PGN structure that acts as a specific ligand for NOD1/CARD4 is $\gamma$-D-glutamyl-meso-diaminopimelic acid (iE-DAP), a signature motif found in most Gram-negative and some Gram-positive bacterial PGNs (Chamaillard et al., 2003;
Girardin et al., 2003a). In contrast, NOD2/CARD15 is a more global bacterial sensor as it interacts with $\mathrm{N}$-acetylmuramyl-L-alanyl-D-isoglutamine [muramyl dipeptide (MDP)], a motif common to both Gram-negative and Gram-positive bacterial PGNs (Girardin et al., 2003b; Inohara and Núňez, 2003).

In the present study we investigated the potential role of NOD1 and NOD2 as cytoplasmic PRRs involved in initiating host IEC innate immunity in response to $C$. jejuni. We observed marked increase in IEC IL-8 and human $\beta$-defensin 2 (hBD2) expression in response to infection with live $C$. jejuni cells. In contrast, fixed-bacteria were significantly impaired in eliciting IEC immune responses. Five hours post infection, live $C$. jejuni infection resulted in the presence of intracellular bacterial cells whereas paraformaldehyde (PFA)-fixed $C$. jejuni exhibited a predominant extracellular location. The presence of intracellular bacteria coupled to potent innate immune induction makes the involvement of cytoplasmic PRRs such as the NOD family more likely in $C$. jejuni-mediated host cellular events.

Specific knock down of NOD1 in Caco-2 cells led to significant reduction in $C$. jejuni-driven innate immune transcriptional activity, gene and protein expression. These effects were observed during infections with two well characterized $C$. jejuni clinical isolates $11168 \mathrm{H}$ and 81-176. Importantly, reduced NOD1 expression resulted in an increase in number of intracellular $C$. jejuni implicating NOD1 as a major PRR responsible for initiating bactericidal defence mechanism(s) against this bacterium. We also provide evidence that NOD2, a close relative of NOD1 plays a minimal role in intestinal epithelial innate immunity to $C$. jejuni.

\section{Results}

Intracellular C. jejuni bacterial component(s) play an important role in eliciting IEC innate immunity

Previous studies have shown that $C$. jejuni induces expression of several chemokines including IL-8 on contact with IECs (Hickey et al., 1999; Hu and Hickey, 2005) and that bacterial de novo protein synthesis is required for IL-8 production (Watson and Galan, 2005). Prior to investigating the role of cytoplasmic NOD proteins as potential PRR(s) for $C$. jejuni, it was pertinent to establish a link between epithelial responses and bacterial localization in our co-culture model system. For this purpose, we compared epithelial responses of live versus PFA-fixed C. jejuni. PFA treatment allows maintenance of the structural integrity of the bacterial cells (albeit with reduced ability for conformational changes) while rendering the bacteria non-viable and unable to execute and participate in active, energy requiring processes. We 
(a)

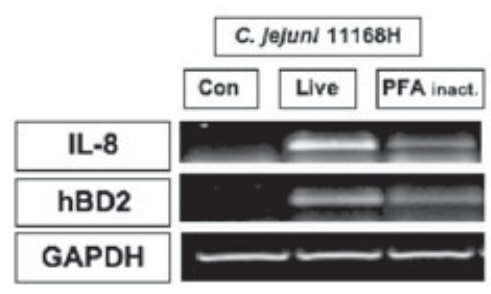

(b)

(c)

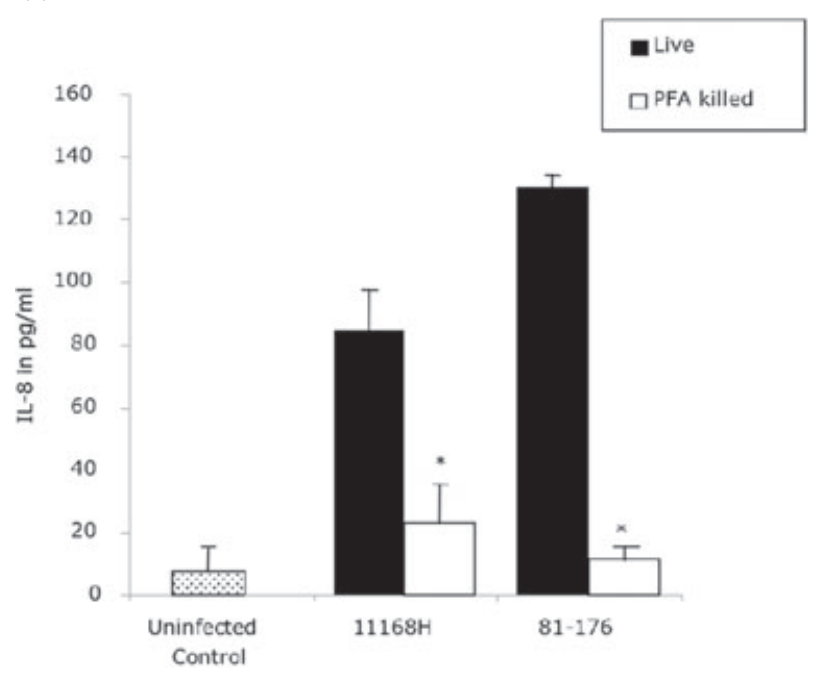

(d)
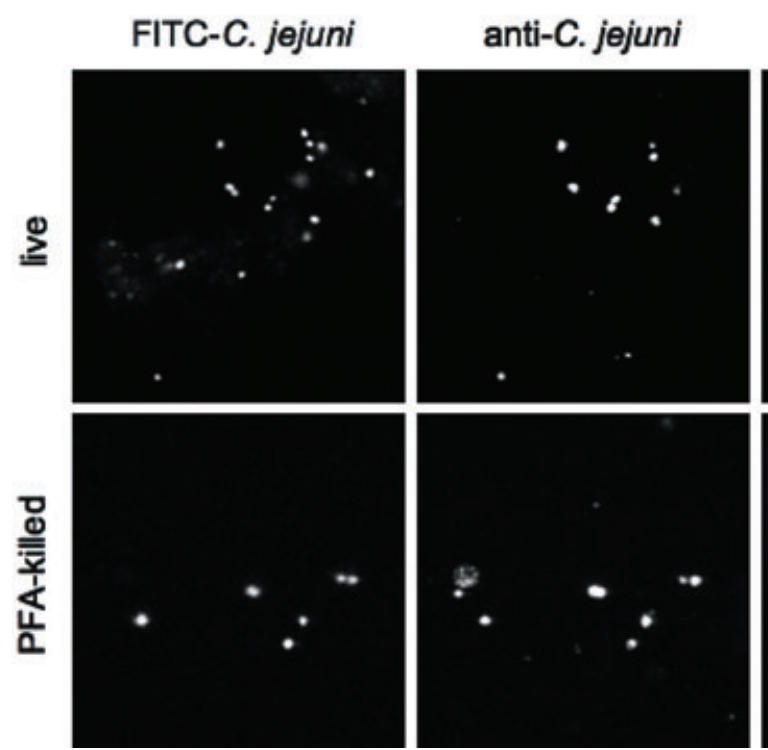

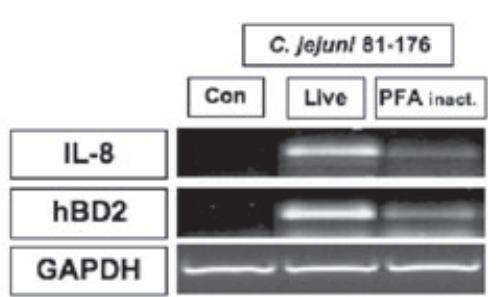

GAPDH

anti-C. jejuni
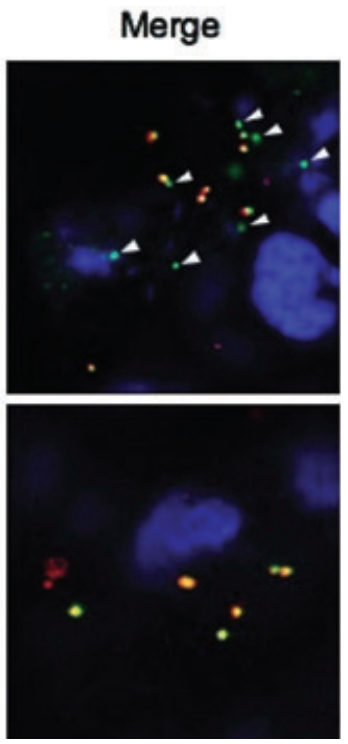

Fig. 1. a-c. Differential induction of intestinal epithelial cell (IEC) IL-8 and hBD2 expression in response to live and paraformaldehyde (PFA)-fixed C. jejuni cells. Caco-2 cells were infected with live or PFA-fixed WT $C$. jejuni strains $11168 \mathrm{H}$ (a) and 81-176 (b). A representative gel for infection with each wild-type strain is shown. Eight hours post infection, IL-8 and hBD2 gene expression was measured by RT-PCR and normalized against GAPDH expression. Quantification of IL-8 protein levels was performed by ELISA (c). Error bars indicate standard error of mean (SEM) obtained from a minimum of two independent experiments performed in duplicate. ${ }^{*} P<0.05$; live versus PFA-fixed C. jejuni cells.

d. Intracellular localization of live $C$. jejuni cells $5 \mathrm{~h}$ post infection. Caco- 2 cells were co-cultured with live or PFA-fixed

FITC-labelled C. jejuni 81-176 (green) for $5 \mathrm{~h}$. To distinguish between intra- and extracellular bacterial localization, non-permeabilized cells were stained with anti- $C$. jejuni antibodies followed by Alexa Fluor 568 conjugated rabbit anti-goat IgG. The latter treatment allowed for additional staining of extracellular

FITC-labelled bacteria leading to a yellow appearance (merging of green FITC and red Alexa Fluor-568). In contrast, intracellular bacteria remained green. Nuclei were counterstained with TO-PRO-3 (blue in merged image). Intracellular bacterial localization is highlighted (arrowheads). A representative image from two experiments (performed in triplicate) is shown. observed potent induction of epithelial IL-8 and hBD2 gene expression in the presence of infection with live C. jejuni $11168 \mathrm{H}$ and $81-176$ cells, with the response markedly reduced on exposure to PFA-fixed cells (Fig. 1a and $b$ ). Potency of infection with live bacteria was also confirmed at the protein level. In comparison PFA-fixed bacteria showed a significant reduction in their ability to induce IL-8 protein (Fig. 1C). Bacterial localization was investigated $5 \mathrm{~h}$ post-infection. C. jejuni was detected both intracellularly (green) and extracellularly (yellow; merged image) following infection with live 81-176 strain (Fig. 1d; merged upper panel). In contrast, PFA-fixed 
(a)

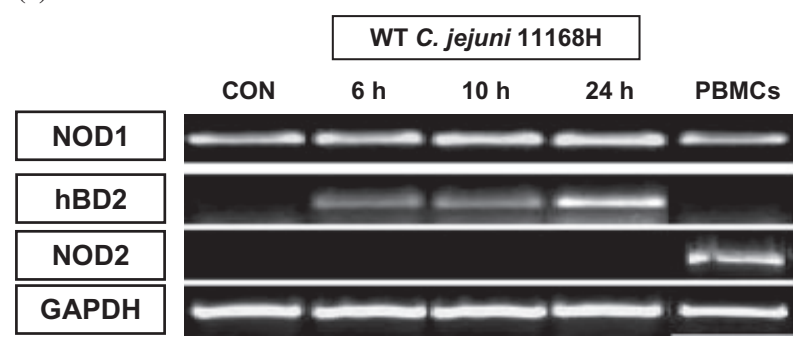

(b)

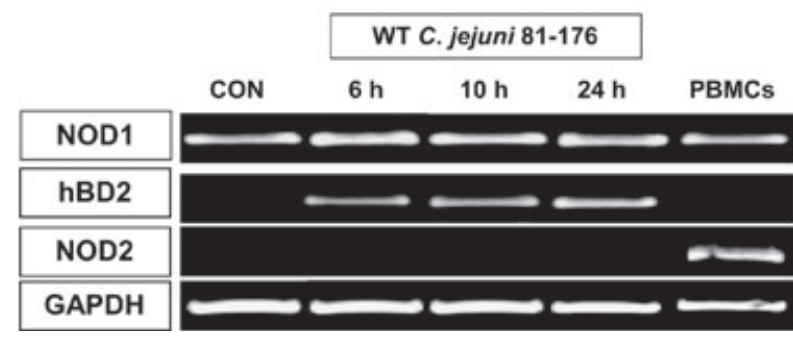

Fig. 2. Intestinal epithelial NOD1 and NOD2 expression is not modulated during $C$. jejuni infection. Caco-2 cell-line were co-cultured with $C$. jejuni wild-type $11168 \mathrm{H}$ (a) or 81-176 (b) strains for up to $24 \mathrm{~h}$. Time-dependant gene expression of NOD1 (upper panel) and NOD2 (third panel) was followed by RT-PCR. In parallel, evidence for infectivity was confirmed by observing increase in hBD2 expression (second panel). Peripheral blood mononuclear cells (PBMCs) served as positive control for NOD2.

bacteria showed mainly extracellular localization (Fig. 1d; merged lower panel). The marked reduction in the presence of intracellular $C$. jejuni cell components(s) during infection with PFA-fixed bacteria may contribute to the observed lack of induction of epithelial innate immunity.

Intestinal epithelial NOD1 and NOD2 gene expression is not modulated in response to $\mathrm{C}$. jejuni

Bacterial adherence to and subsequent invasion of the IEC is a well established early event in C.jejunimediated disease pathogenesis (Konkel and Joens, 1989; Szymanski et al., 1995; Monteville et al., 2003). The causal association of presence of intracellular bacteria with potent IEC responses (Fig. 1) added weight to our initial hypothesis that epithelial cytoplasmic NOD protein(s) may be potential PRR(s) for C. jejuni. We confirmed the constitutive expression of NOD1 in Caco-2 (Fig. 2; upper panel) and HT-29 cell-lines (data not shown). Interestingly, no modulation of NOD1 expression was noted during $C$. jejuni infection up to $24 \mathrm{~h}$ post infection, irrespective of bacterial strain tested (Fig. 2a and b) or cell-line used. Evidence for infectivity was sought in parallel. This was investigated by following the expression of hBD2; a bactericidal molecule whose expression is known to be dependent on NOD1 engagement (Boughan et al., 2006). No hBD2 expression was noted in control, uninfected Caco-2 cell-line (Fig. 2; second panel). In response to infection with two different wild-type strains (11168H and 81-176), we observed induction of hBD2; with initial expression noted as early as $6 \mathrm{~h}$ post infection (Fig. 2; second panel). To delineate a role for NOD2 as a potential PRR for C. jejuni, we followed the expression of this molecule during infection. NOD2 expression was not observed in either uninfected or C. jejuni-infected Caco-2 cells throughout the $24 \mathrm{~h}$ course of infection (Fig. 2; third panel). Similarly, no NOD2 expression was noted in infected HT-29 cells (data not shown). Macrophages in peripheral blood mononuclear cells (PBMCs) are known to express NOD2 and were therefore included in each experiment as a positive control.

The presence of NOD1 small interfering (si) RNA inhibits $I L-8$ and $h B D 2$ gene expression in response to C. jejuni infection

We next wished to establish if intestinal epithelial NOD1 was involved in $C$. jejuni-mediated epithelial responses. Two distinct siRNA sequences specifically targeting NOD1 (siNOD1 $a$ and b) were transiently transfected into Caco-2 cells and NOD1 gene knock down was investigated $48 \mathrm{~h}$ post-transfection by reverse transcription polymerase chain reaction (RT-PCR). Specificity of gene silencing was confirmed (Fig. $3 a$ and b, third panel). Importantly, transfection of a non-targeting, control siRNA sequence (siNEG) did not affect NOD1 expression (Fig. $3 a$ and b, third panel). Transfected Caco-2 cells were co-cultured with 11168H (Fig. 3a) and 81-176 (Fig. 3b) strains for $8 \mathrm{~h}$. IL-8 and hBD2 gene expression was inhibited following transfection with siNOD1 (a and b), implicating NOD1 in C.jejuni-mediated IEC innate immune responses.

More detailed analysis of the role of NOD1 in C. jejunidriven IEC transcriptional and translational innate immunity was sought. We found a dose-dependent inhibitory effect of siNOD1 on $C$. jejuni-mediated IL-8 promoter activity (Fig. 3c and d). Dose-dependency was tested at 10 and $20 \mathrm{nM}$ concentration for siNOD1 $a$ and $b$ sequences. Thirty to fifty per cent inhibition of IL-8 transcription activity index was routinely achieved in the presence of transfected siNOD1 irrespective of the bacterial strain or sequence tested (Fig. $3 c$ and d). In parallel experiments, siNEG sequence was found to have no effect on IL-8 promoter activity, further highlighting specificity of NOD1 knockout and its biological consequences on IL-8 promoter activity. Once the greater inhibition of siNOD1 sequences at $20 \mathrm{nM}$ was established, the effect of this concentration on hBD2 promoter activity was tested. As shown in Fig. 3e and f, there was 50-60\% reduction in $C$. jejuni-mediated hBD2 promoter activity in the presence of siNOD1 a and b, confirming a critical role 
(a)

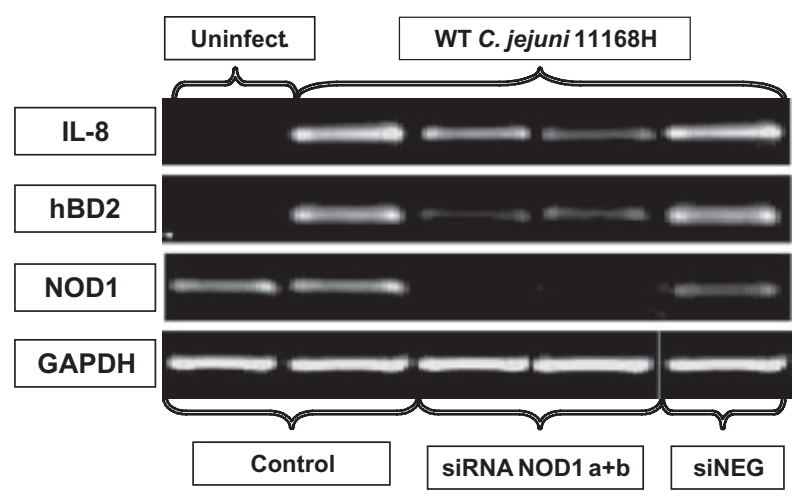

(c)

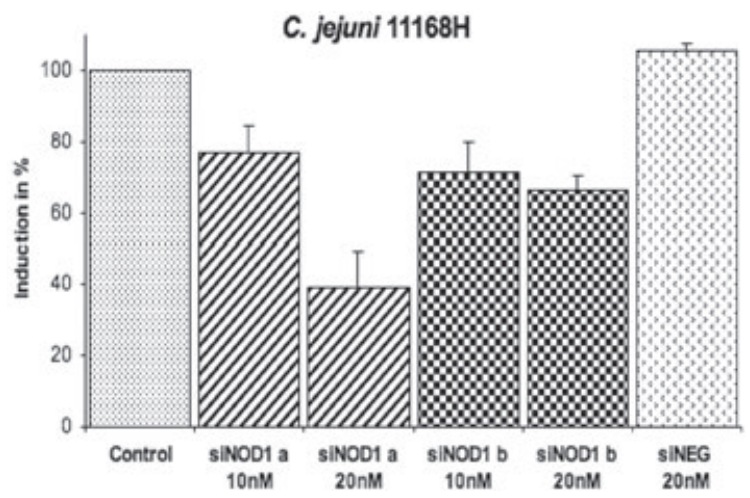

(e)

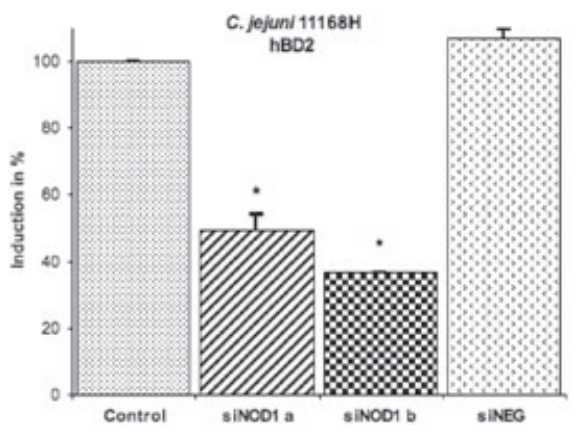

(g)

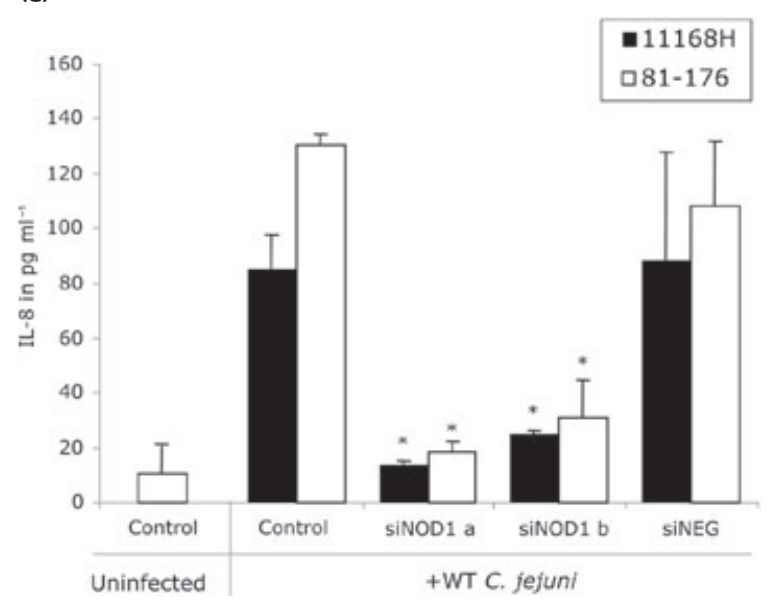

(b)

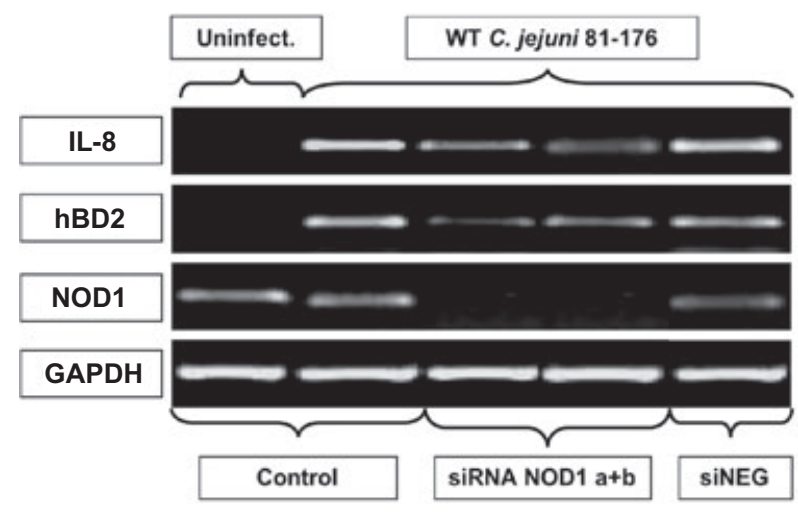

(d)

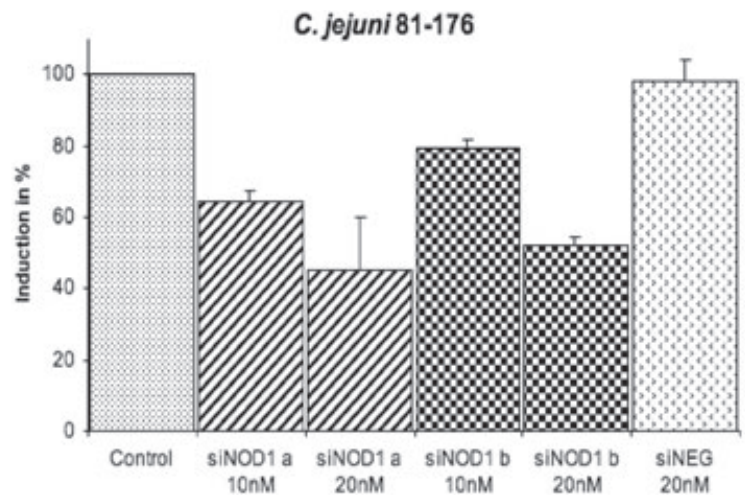

(f)

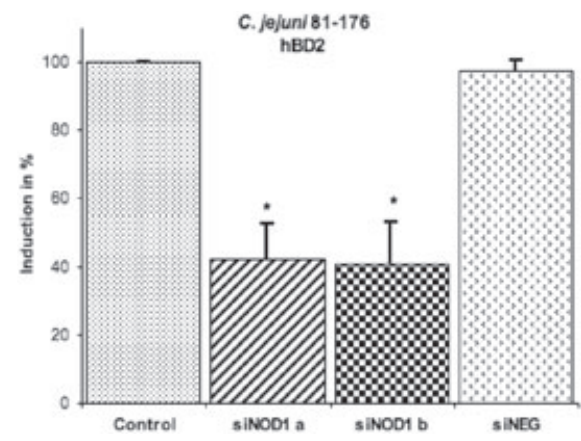


Fig. 3. Inhibition of $C$. jejuni-mediated IL-8 and hBD2 expression in the presence of NOD1 small interfering (si) RNA. Caco-2 cells were reverse-transfected with two distinct siRNA sequences targeting NOD1 (siNOD1 a and b) and a non-targeting (siNEG) sequence. For luciferase reporter gene analyses, cells were cotransfected with promoter constructs for IL-8 (c and d) and hBD2 (e and f) 24 h post siRNA treatment. Following a further $24 \mathrm{~h}$ incubation transfected cells were co-cultured with $C$. jejuni wild-type strains for $8 \mathrm{~h}$.

$a$ and b. IL-8 and hBD2 gene expression was followed post infection by RT-PCR. A representative gel for infection with each wild-type strain is shown.

c and d. siNOD1 dose-dependent inhibition of $C$. jejuni 11168H (c) and 81-176 (d)-mediated IL-8 promoter activity.

e and f. Significant inhibition of $C$. jejuni-mediated hBD2 transcriptional activity in the presence of $20 \mathrm{nM}$ siNOD1 targeting sequences.

g. Marked inhibition of $C$. jejuni-mediated IL-8 protein production in the presence of siNOD1 targeting. Treatment with non-targeting siNEG had no significant effect on IL-8 protein levels as measured by ELISA. ${ }^{*} P<0.05$ versus IL-8 and hBD2 induction in untreated and non-targeting siRNA treated Caco-2 cells.

for this intracellular PRR in C. jejuni-mediated IEC responses. As observed for IL-8 (Fig. $3 c$ and d), infections performed in the presence of siNEG had minimal effect on hBD2 transcriptional activity.

NOD1 gene silencing not only inhibited bacterialinduced IL-8 promoter and gene function in Caco-2 cells but also markedly reduced protein expression (Fig. $3 g$ ). Induction of IL-8 protein in response to infection with C. jejuni $11168 \mathrm{H}$ and $81-176$ strains was significantly inhibited in the presence of both siNOD1 $a$ and $b$ sequences with siNEG exhibiting no significant effect. This series of experiments unequivocally highlighted NOD1 as a critical sensor and signalling molecule in C. jejuni-mediated IEC responses.

\section{NOD2 plays a minimal role in intestinal epithelial immune defence against $\mathrm{C}$. jejuni}

Experiments described above showed that NOD2 gene expression was not seen in resting or $C$. jejuni-stimulated epithelial cells (Fig. 2). However, during an in vivo infection, intestinal epithelial homeostasis is likely to be influenced indirectly by neighbouring inflammatory immune cells and their secretory products such as cytokines, molecules known to modulate NOD2 expression (Gutierrez et al., 2002; Rosenstiel et al., 2003). To establish if epithelial NOD2 (when expressed under inflammatory conditions) may also act as a potential PRR for $C$. jejuni, we transiently transfected Caco-2 cells with a plasmid overexpressing NOD2. NOD2 gene expression $48 \mathrm{~h}$ posttransfection was confirmed by RT-PCR (Fig. 4a and C; third panel). Control and NOD2 transfected Caco-2 cells were exposed to $C$. jejuni wild-type strains $11168 \mathrm{H}$ (Fig. 4a) and 81-176 (Fig. 4c). Infection with either strain resulted in no enhanced IL-8 or hBD2 gene expression (Fig. $4 \mathrm{a}$ and C). Similarly, no increase in C. jejunimediated IL-8 and hBD2 promoter activity was noted in the presence of NOD2 when compared with control cells lacking NOD2 (Fig. 4b and d).

Streptococcus pneumoniae (a causative agent for bacterial meningitis) transiently invades epithelial cells and uses NOD2 as a PRR (Opitz et al., 2004). To confirm that the transfected NOD2 gene in our cell culture system was biologically active, we included S. pneumoniae infection as a control. As noted for gene expression, the presence of NOD2 had no effect on the levels of IL-8 protein production in response to $C$. jejuni strains $11168 \mathrm{H}$ or $81-176$ (Fig. 4e). In contrast, a significant increase in IL-8 protein levels was observed in NOD2-transfected Caco-2 cells in response to S. pneumoniae compared with infection in control, untransfected cells. These data clearly suggest that, unlike S. pneumoniae, $C$. jejuni does not engage NOD2 in mediating IEC innate responses.

\section{Intestinal epithelial cell NOD1 engagement mediates antimicrobial defence against $\mathrm{C}$. jejuni}

Although the data presented above highlights NOD1 as a major PRR in IL-8 and hBD2 expression (Fig. 3), the impact of IEC immunity on subsequent bacterial-host interactions remains poorly defined. To investigate the biological consequence of NOD1-mediated antimicrobial activity on $C$. jejuni, bacterial co-culture studies were performed on control untransfected, siNEG, siNOD1a, siNOD1b and NOD2 transfected Caco-2 cells. $20 \mathrm{~h}$ post infection with 81-176 strain, cells were washed and subjected to a standard gentamicin protection assay. Lysed cell suspensions were diluted and viable intracellular bacteria enumerated by counting the colony-forming units (cfu) on blood agar plates. Each experiment was performed in triplicate. Data of two similar experiments are schematically shown in Fig. 5. No significant difference in the number of intracellular bacteria was noted between control untransfected Caco-2 cells and those transfected with siNEG. This was an important observation as it highlighted that introducing a non-targeting siRNA molecule did not interfere with host responses under investigation. Most importantly, the specific knock-down of NOD1 (siNOD1 a and b) during infection greatly enhanced the number of intracellular $C$. jejuni cells. Our study is the first to implicate IEC NOD1 function in modulating the intracellular presence of $C$. jejuni. In contrast, the additional presence of NOD2 did not appear to modulate the number of intracellular bacteria when compared with control untransfected cells. 
(a)

(c)

\section{C. jejuni 11168H}

\begin{tabular}{|c|}
\hline IL-8 \\
\hline hBD2 \\
\hline NOD2 \\
\hline GAPDH \\
\hline
\end{tabular}

(b)

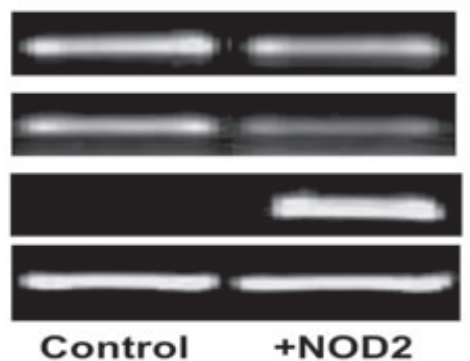

Control +NOD2

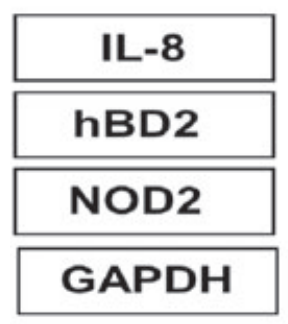

(d)

\section{C. jejuni 81-176}

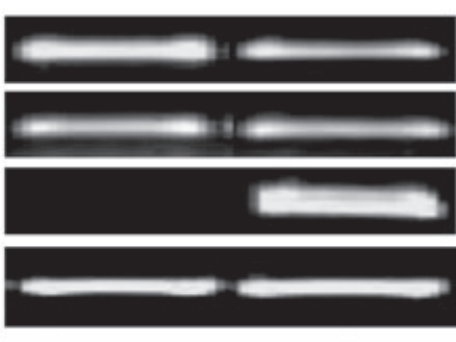

Control +NOD2

Caco-2 + NOD2 100ng

C. jejuni $11168 \mathrm{H}$

\section{Caco-2 + NOD2 100ng \\ C. jejuni 81-176}
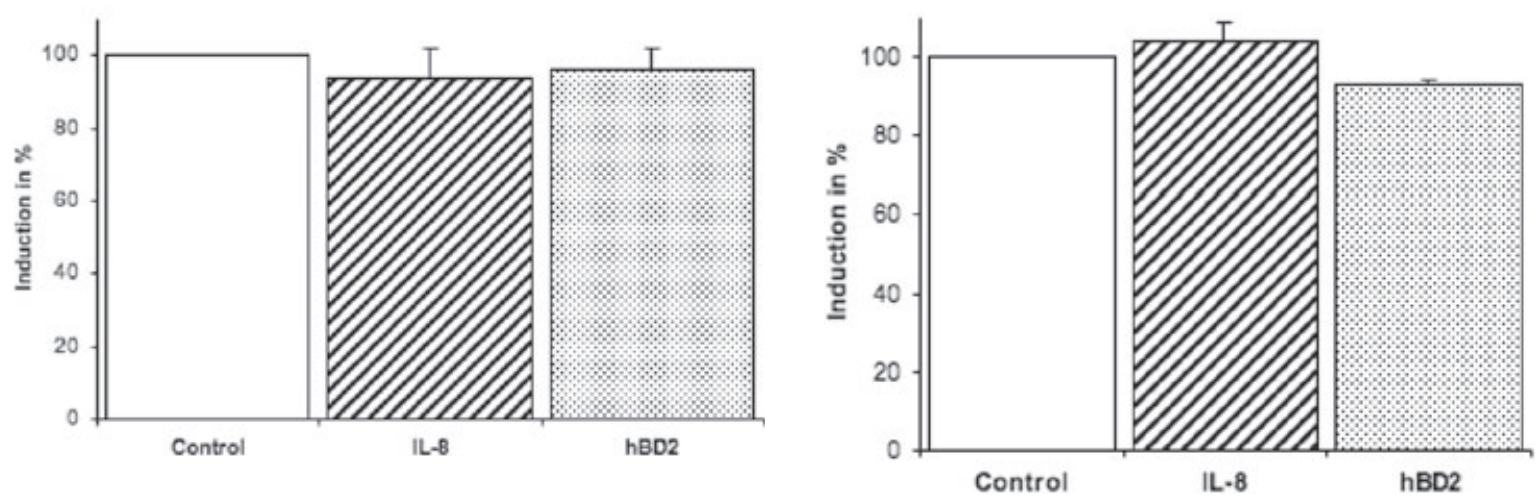

(e)
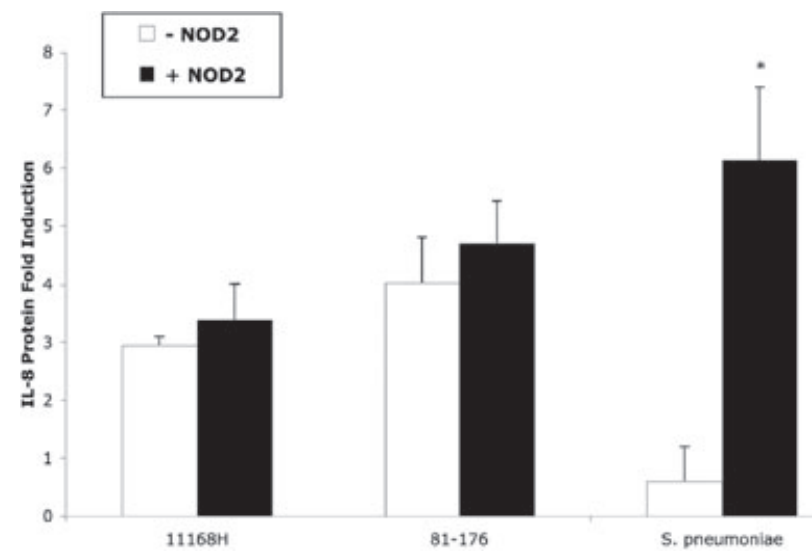

Fig. 4. NOD2 plays a minimal role in $C$. jejuni-mediated IL-8 and hBD2 induction. Caco-2 cells were transiently transfected with NOD2 overexpressing plasmid for $48 \mathrm{~h}$ followed by infection with $C$. jejuni WT $11168 \mathrm{H}$ (a and b) or 81-176 (c and d) strains for $8 \mathrm{~h}$. IL-8 and hBD2 gene expression was analysed by RT-PCR $(a$ and $c$ ) and their transcriptional activity quantified by promoter luciferase reporter assay (b and d). The potential effect of the presence of NOD2 on bacterial-mediated IL-8 protein level was also investigated (e). Encapsulated S. pneumoniae (serotype F19) was included as a positive control as it is known to use NOD2 as a PRR. 


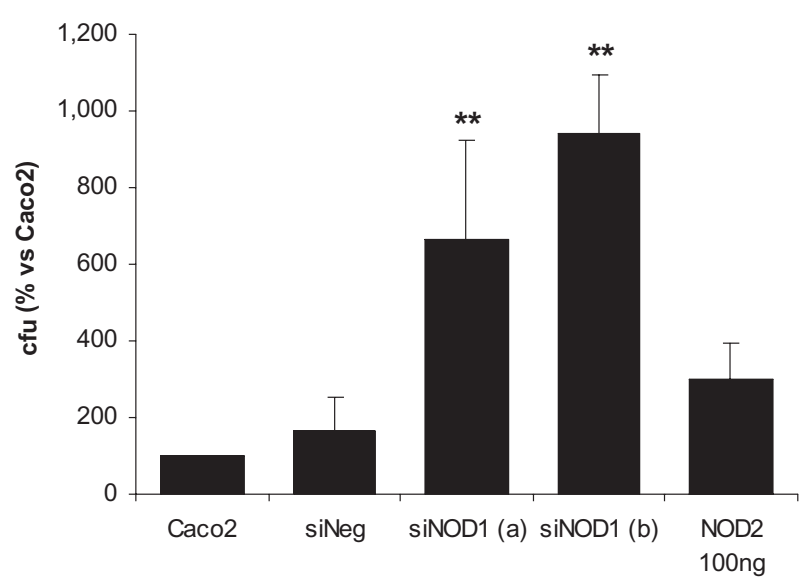

Fig. 5. Absence of intestinal epithelial NOD1 leads to increase in number of intracellular $C$. jejuni cells. Caco-2 cells were reverse-transfected with siRNA (sequences a and b) targeting NOD1 or with siNEG or with plasmid expressing NOD2.

Non-treated Caco-2 cells served as control. Forty-eight hours post-transfection, cells were co-cultured with live WT $C$. jejuni 81-176 for $20 \mathrm{~h}$ prior to enumeration of intracellular bacteria. Data represent average percentage colony-forming units (cfu) obtained in treated versus untreated Caco-2 cells (the latter set as 100\%). Statistical analysis of two to three independent experiments performed in triplicate is shown. ${ }^{* *} P<0.001$ versus untreated Caco-2 cells.

\section{Discussion}

The pathogenesis of $C$. jejuni-mediated enterocolitis and related complications in humans remains ill defined. The self-limiting nature of infection coupled with lack of a reliable animal model reflecting human campylobacteriosis have proved to be major stumbling blocks to our current understanding of disease aetiology. Despite the availability of the genome sequences of the three strains NCTC11168, RM1221 and 81-176 (Parkhill et al., 2000; Fouts et al., 2005; Hofreuter et al., 2006), little is known about the mechanism(s) by which $C$. jejuni triggers host responses.

Once bacterial contact with intestinal epithelium is established, enteropathogens rely on multiple strategies to ensure optimal, dynamic interactions with the host. One such strategy that $C$. jejuni shares with other intestinal pathogens such as Salmonella, Shigella and Yersinia species is host cell invasion (Kopecko et al., 2001; Ellison et al., 2004; Nhieu et al., 2005). Activation of multiple IEC signal transduction pathways is known to occur upon adhesion and invasion of $C$. jejuni, in particular IL-8 production has been shown to be intimately linked with these early cellular events (Konkel and Cieplak, 1992; Oelschlaeger et al., 1993; Kopecko et al., 2001; Biswas et al., 2003; Mooney et al., 2003; Hu and Hickey, 2005; Watson and Galan, 2005).

In the present study we used two different $C$. jejuni wild-type strains $(11168 \mathrm{H}$ and 81-176) known to exhibit varying invasive capacity (MacCallum et al., 2005); (A.
Elmi and N. Dorrell, unpub. data). In addition, C. jejuni 81-176 harbours a putative virulence plasmid ( $p$ Vir) encoding a potential type IV secretion system, which has been implicated in invasion of intestinal epithelia (Bacon et al., 2000). Interestingly, in our co-culture studies both $11168 \mathrm{H}$ and $81-176$ strains elicited similar IL-8 gene and protein induction, the differences noted were not statistically significant (Fig. 1a-c). We also observed similar induction (three- to four-fold increase) in IL-8 and hBD2 promoter transcriptional activity in response to the two strains in HT-29 cells (data not shown). Our data not only confirms previous studies where a trend for increased IL-8 protein production with more invasive $C$. jejuni strains has been noted (Fig. 1c; Watson and Galan, 2005; Johanesen and Dwinell, 2006), but we extend these findings by suggesting that $11168 \mathrm{H}$ and $81-176$ do not exhibit significantly different effects on IEC immune gene transcription.

Despite the lack of complete correlation between the degree of $C$. jejuni invasion and IEC IL-8 protein induction, the process of 'invasion' itself is a crucial event involved in eliciting innate immune responses. Experiments conducted in the presence of PFA-fixed bacteria showed marked absence of intracellular $C$. jejuni cells and correspondingly, IECs exhibited weak IL-8 protein production, thus clearly identifying the requirement for C. jejuni cell components within the IEC cytoplasm for optimal host response.

An ancient, universal strategy that allows hostpathogen cross-talk to take place is the interaction of microbial PAMPs with corresponding host receptors aptly called PRRs (Akira, 2006; Franchi et al., 2006). TLRs were the first family to be implicated as PRRs in host innate recognition. Unlike Salmonella which engages host TLR5, C. jejuni flagellin has been found to have weak immune-stimulatory properties with minimal interaction with IEC TLR5 (Andersen-Nissen et al., 2005; Watson and Galan, 2005; Johanesen and Dwinell, 2006). The information that bacterial invasion is crucial for IEC immunity, coupled with minimal involvement of TLR5 led us to hypothesize that the intracellular NOD family could be likely $\operatorname{PRR}(\mathrm{s})$ for $C$. jejuni.

Peptidoglycans (PGNs) are ubiquitous constituents of bacterial cell walls. PRRs involved in PGN recognition are the intracellular NOD proteins, members of the Apaf-1/ CARD superfamily (Inohara et al., 2002; Philpott and Girardin, 2004; Franchi et al., 2006; Fritz et al., 2006; Strober et al., 2006). NOD1 is constitutively expressed in IEC with minimal expression of its close homologue NOD2 observed under control conditions. In contrast, NOD2 is abundant in Paneth cells of the small intestine and in antigen-presenting cells (Ogura et al., 2001; Kobayashi et al., 2005). We first wished to investigate if C. jejuni infection could modulate the expression of the 
potential PRR(s). Using two different cell-lines (Caco-2 and HT -29; data for the latter cell-line not shown) and two bacterial wild-type strains in co-culture experiments, we found no significant modulation of NOD1 expression in the $24 \mathrm{~h}$ infection period (Fig. 2; top panel). This was an important observation as it suggests that the bacterium does not directly modulate NOD1 expression as an early immune evasion strategy. However, due to the limitations of an in vitro cell-line model of infection, one cannot rule out bacterial-driven changes in NOD1 expression and function in an ongoing infection in vivo. Cytokines such as IFN- $\gamma$ are known to augment NOD1 expression (Hisamatsu et al., 2003a) suggesting greater complexity to C. jejuni/epithelial NOD1 interactions in an on-going inflammatory episode are likely. NOD2 gene expression was not detected in control Caco-2 cells (Fig. 2; third panel) and infection with either $C$. jejuni strain did not result in NOD2 induction, suggesting that it is NOD1 and not NOD2 that is likely to be a potential PRR for $C$. jejuni in our model system. In the same experiments, we confirmed appropriate infectivity by following the expression of hBD2, a peptide whose expression is NOD1 activationdependent (Boughan et al., 2006). Induction of hBD2 in the absence of NOD2 clearly implicated NOD1 as a potential intracellular sensor for $C$. jejuni.

Next, we sought evidence for a functional role for NOD1 in $C$. jejuni infection. For this purpose we transiently transfected two NOD1 siRNA sequences prior to exposure of cells to $C$. jejuni. We observed dose-dependent inhibition in IL-8 promoter luciferase activity in the presence of both sequences with significant reduction at $20 \mathrm{nM}$ concentration (Fig. 3). Although marked knock-down of the NOD1 gene was observed (Fig. $3 a$ and b) its corresponding inhibitory effect on IL-8 and hBD2 gene and promoter function (Fig. $3 a-f$ ) ranged between $40 \%$ and $60 \%$, suggesting NOD1-independent signalling events are also involved in IEC innate immune gene regulation. Several studies have implicated MAP kinase pathways in C. jejuni-mediated IL-8 production (MacCallum et al., 2005; Watson and Galan, 2005) and it is most likely that they are also operative in our model system.

Studies by Podolsky and colleagues have suggested a role for NOD2 in intestinal epithelial defence against Salmonella infection (Hisamatsu et al., 2003b). In our study, overexpression of NOD2 by transient transfection did not augment innate defence gene expression in response to C. jejuni infection (Fig. 4). To validate the functionality of transfected NOD2 in our culture system, we included live S. pneumoniae infection as a positive control as Optiz and coworkers have elegantly demonstrated NOD2 as the intracellular PRR for this bacterium (Opitz et al., 2004). Why Samonella and Campylobacter, two Gram-negative enteropathogens exhibit such contrasting requirement for NOD2 warrants further investigation.
Finally, if antibacterial immunity is generated in response to $C$. jejuni infection via NOD1 activation (e.g. hBD2 production), one can hypothesize that absence of this armory is likely to enhance bacterial invasion and/or survival. We followed the biological consequence of NOD1 knock-out on C. jejuni infection. We found a marked increase in the number of invasive bacteria $20 \mathrm{~h}$ post-infection in cells treated with siNOD1a or $b$ sequences (Fig. 5), suggesting that NOD1-mediated cellular events do contribute to the number of intracellular bacteria, whether this is due to increased invasion or survival or due to decrease in bacterial transcytosis remains a question for future work (McKay et al., 2007).

The identification of NOD1 as a major sensor to enteroinvasive Escherichia coli led Kagnoff and colleagues to propose that NOD1 signalling in the IEC may provide a backup mechanism for rapidly activating innate immunity during infection by highly invasive pathogenic Gramnegative enteropathogens (Kim et al., 2004). Our study implicating NOD1 as a major intracellular PRR for C. jejuni, the most common cause of bacterial enterocolitis lends further support for a critical role for NOD1mediated immunity at the GI mucosal surface. With the identity of NOD1 as the PRR for $C$. jejuni now known, it is tempting to speculate about the link between degree of C. jejuni invasion and epithelial innate responses. With limited NOD1 molecules in an epithelial cell, a direct correlation between low levels of $C$. jejuni invasion and NOD1 activation and subsequent IL-8 induction is quite likely. However, once NOD1 and bacterial PGN interactions reach saturation, enhanced invasion leading to the presence of higher numbers of intracellular bacteria may not trigger further chemokine responses. Further studies are now required to investigate $C$. jejuni-mediated signalling via NOD1 in more detail. Activation of both TLRs and Nod-like receptors (NLRs) by different bacterial PAMPs is emerging as an important factor in mounting an inflammatory response, further priming of cells with $P G N$ resulting in activation of NLRs is known to have a synergistic effect on TLR signalling (Kufer and Sansonetti, 2007). Insight into mechanism(s) involved in $C$. jejuni PGN delivery, the subsequent recognition by NOD1 and possible interplay between NLR and TLR signalling pathways will shed greater light on the role of $C$. jejuni invasion in eliciting host responses.

\section{Experimental procedures}

\section{Bacterial strains and culture conditions}

The $C$. jejuni wild-type strains used in this study were 81-176, a gastroenteritis isolate from a multistate outbreak from contaminated milk (Korlath et al., 1985), and $11168 \mathrm{H}$, a hypermotile isolate that was derived from the source of NCTC11168 used for genome sequencing, which shows high levels of intestinal colo- 
nization in a chick colonization model (Jones et al., 2004). C. jejuni was grown at $37^{\circ} \mathrm{C}$ in a microaerobic chamber (Don Whitley Scientific, Shipley, UK) containing $85 \% \mathrm{~N}_{2}, 5 \% \mathrm{O}_{2}$ and $10 \% \mathrm{CO}_{2}$ on blood agar plates consisting of Columbia agar base (Oxoid, Basingstoke, UK) supplemented with $7 \% \mathrm{v} / \mathrm{v}$ defibrinated horse blood (TCS Microbiology, Botolph Calydon, UK) or in Mueller-Hinton (MH) broth (Oxoid). Bacteria were grown on blood agar plates for $24 \mathrm{~h}$ prior to use in co-culture experiments. Bacterial inactivation was achieved by PFA (4\%, 15 min followed by three washes in tissue-culture media) treatment. A hundred per cent inactivation was confirmed by viable counting.

Streptococcus pneumoniae was prepared as described previously (Opitz et al., 2004). Briefly, WT encapsulated S. pneumoniae (serotype F19) was grown on Columbia agar plates supplemented with $7 \% \mathrm{v} / \mathrm{v}$ defibrinated horse blood (as described above) at $37^{\circ} \mathrm{C}$ with $5 \% \mathrm{CO}_{2}$ over $24 \mathrm{~h}$. Single colonies were resuspended in Todd-Hewitt broth (Sigma-Aldrich, Gillingham, UK) supplemented with $0.5 \%$ yeast extract and incubated at $37^{\circ} \mathrm{C}$ for 3-4 h (100 r.p.m.) to reach midlogarithmic phase $\left(A_{600}-0.4\right)$. Bacteria were harvested by centrifugation and resuspended in tissue culture medium to a final concentration of $2 \times 10^{8} \mathrm{cfu} \mathrm{ml}^{-1}$.

\section{C. jejuni intestinal epithelial co-culture studies}

Reagents for mammalian tissue culture, RNA extraction and RT-PCR were obtained from Invitrogen (Paisley, UK) unless stated otherwise. The human intestinal epithelial cell-line Caco-2 was cultured in Dulbecco's modified essential media (DMEM) plus GlutaMAX supplemented with $10 \%$ fetal calf serum (FCS; Sigma-Aldrich, Gillingham, UK), $100 \mathrm{U} \mathrm{ml}^{-1}$ penicillin, $100 \mu \mathrm{g} \mathrm{ml}^{-1}$ streptomycin, and $1 \% \mathrm{w} / \mathrm{v}$ non-essential amino acids and maintained at $37^{\circ} \mathrm{C}$ in $5 \% \mathrm{CO}_{2}$ and $95 \%$ air. For co-culture experiments, cells were grown in 6 -well plates to $>90 \%$ confluence and maintained in low serum $(0.1 \%)$ and antibiotic-free media overnight prior to co-culture with $10^{8} \mathrm{cfu} \mathrm{ml}^{-1}$ [multiplicity of infection $(\mathrm{MOI})=100$ ] of bacterial cells. Infections were terminated by removing the supernatant followed by two washes in Phosphate Buffered Saline (PBS). Cells and supernatants were frozen at $-80^{\circ} \mathrm{C}$ until required.

\section{RNA extraction and RT-PCR}

Total RNA was isolated using a monophasic solution of phenol and guanidine thiocyanate (TRIZOL) followed by chloroform extraction and isopropanol precipitation. Total RNA was quantified by spectroscopy. Five micrograms of total RNA were routinely reverse-transcribed to $\mathrm{cDNA}$ at $42^{\circ} \mathrm{C}$ with $1 \mu \mathrm{g}$ of oligo-dT primer (Amershan-Pharmacia, St. Albans, UK), $1 \mathrm{mM}$ of each deoxynucleotide triphosphate (dNTPs) and Moloney Murine Leukemia Virus (MMLV) reverse transcriptase in a volume of $20 \mu \mathrm{l}$, following manufacturer's protocol. Five microlitres $(1 \mu \mathrm{l}$ for the housekeeping gene glyceraldehyde-3-phosphate dehydrogenase; GAPDH) of cDNA were amplified in the presence of $20 \mathrm{pmol}$ of each oligonucleotide primer (Sigma-Aldrich, Gillingham, UK), $1.5 \mathrm{mM} \mathrm{MgCl} 2,200 \mu \mathrm{M}$ dNTPs and 0.5 units of Taq polymerase. IL-8 and hBD2 primer sequences were as described previously (Zilbauer et al., 2005).

NOD-1 primer sequences were:

- gtTGtCCAAAGCCAAACAGAAACTC (sense); and

- CAGCATCCAGATGAACGTG (antisense).
NOD-2 primer sequences were:

- ATGTGCTCGCAGGAGGCTTtTCAGGCA (sense); and

- ATGTGCTCGCAGGAGGCTTTTCAGGCA (antisense).

A 3 min hot start at $94^{\circ} \mathrm{C}$ was followed by amplification (denaturation at $94^{\circ} \mathrm{C}$ for $90 \mathrm{~s}$, annealing $60^{\circ} \mathrm{C}$ for $90 \mathrm{~s}$ and extension at $72^{\circ} \mathrm{C}$ for $90 \mathrm{~s}$ ). PCR was allowed to continue for 34-37 cycles ensuring reaction termination in the linear phase. PCR products were visualized by agarose gel electrophoresis and analysed by densitometry.

\section{Interleukin-8 enzyme-linked immunosorbant assay (ELISA)}

Supernatants of control and infected Caco-2 cells were collected and centrifuged for $10 \mathrm{~min}$ at 12000 r.p.m. to pellet residual bacteria and cells. IL-8 concentration was assessed using a commercially available sandwich ELISA kit according to manufacturer's instructions (R\&D Systems, Abingdon, UK).

\section{Demonstration of C. jejuni invasion by confocal microscopy}

Bacterial invasion of live versus PFA-fixed C. jejuni was investigated using confocal microscopy. Fluorescent labelling of WT C. jejuni 81-176 was performed by incubating bacteria in PBS containing $0.1 \mathrm{mg} \mathrm{ml}^{-1} \mathrm{FITC}$ (Sigma-Aldrich, Gillingham, UK) for $15 \mathrm{~min}$ at room temperature. Bacteria were washed twice in PBS to remove unbound FITC and resuspended in antibioticfree DMEM medium supplemented with $1 \%$ FCS. PFA inactivation of FITC-labelled bacteria was performed as described above. Confluent Caco-2 cells grown on coverslips were co-cultured with live or PFA-inactivated FITC-labelled C. jejuni (MOI of 100) in DMEM for $5 \mathrm{~h}$. Following washes with PBS, cells were fixed in $4 \%$ PFA for 20 min. Non-specific binding was blocked by incubating cells with $1 \%$ BSA for $45 \mathrm{~min}$. Extracellular bacteria were labelled with unconjugated goat anti- $C$. jejuni antibodies (Kirkegaard and Perry Laboratories, Maryland, USA) at a concentration of $5 \mathrm{\mu g} \mathrm{ml}^{-1}$ for $60 \mathrm{~min}$ at room temperature followed by incubation with Alexa Fluor 568-conjugated rabbit anti-goat IgG (Molecular Probes, Eugene, Oregon, USA) for $30 \mathrm{~min}$. Bacteria and cell nuclei were counterstained with TO-PRO-3 (Molecular Probes) for $30 \mathrm{~min}$. Co-cultures were visualized with a Radiance 2100 confocal laser scanning microscope equipped with an Argon-Krypton laser and a red diode (Bio-Rad, UK).

\section{Transient transfection of $I L-8$ and hBD2 promoter constructs}

For promoter transcriptional analyses, Caco-2 cells were seeded in a 96-well plate at a density of $2 \times 10^{4}$ cells well $^{-1}$ in $200 \mu \mathrm{l}$ of DMEM and transient transfections performed at 60-80\% cell confluence. Prior to transfection, FuGene reagent (Roche, Lewes, UK) and Opti-MEM (Invitrogen) were mixed and incubated at room temperature for a minimum of $15 \mathrm{~min}$. DNA was added in a ratio of 4:1 (FuGene in $\mu$ l: DNA in $\mu \mathrm{g}$ ) as recommended by the manufacturer. Amount of DNA transfected was equalized among experiments by the addition of varying amounts of empty vector (pcDNA). Test promoter-luciferase constructs IL-8 (kind gift from Dr A.G. Bowie, Dublin) or hBD2 
2414 M. Zilbauer et al.

(Boughan et al., 2006) were cotransfected (60 ng well ${ }^{-1}$ ) with Renilla luciferase construct $\left(20 \mathrm{ng} \mathrm{well}^{-1}\right)$, the latter used to account for cell loss and transfection efficiency. The mixture was added directly to cultured 96-well plates and incubated at $37^{\circ} \mathrm{C}$ for $24 \mathrm{~h}$. For bacterial co-culture experiments, media was replaced by $100 \mu \mathrm{l}$ of DMEM containing C. jejuni cells (moi 100). $20 \mathrm{~h}$ post infection, cells were washed with $200 \mu \mathrm{l}$ of PBS prior to addition of passive lysis buffer (Promega, Southampton, UK). Firefly and Renilla luciferase activity was measured using a 96-well plate luminometer (Lucy 1; Anthos Biotech, Salzburg, Austria).

Small interfering (si) RNA experiments siRNA sequences targeting NOD1 (Sequence 1: sense GGC CAA AGU CUA UGA AGA Utt, Sequence 2: sense GGG UGA GAC CAU CUU CAU $\mathrm{Ctt}$ ) and a non-targeting negative (siNEG) control sequence (catalogue number AM 4611) were all purchased from Ambion (Huntingdon, Cambridge UK). Caco-2 cells were reversetransfected with siRNA using siPORT NeoFX Transfection Reagent (Ambion). siRNA was prepared in Opti-MEM serum-free medium (Invitrogen) by mixing 0.7 or $0.8 \mu \mathrm{l}$ of the transfection reagent with 10 or $20 \mathrm{nM}$ siRNA, respectively, at room temperature for $10 \mathrm{~min}$. Caco- 2 cells $\left(8 \times 10^{3}\right.$ cells well $\left.^{-1}\right)$ were transferred to a 96 -well plate containing siRNA transfection reagent complexes, allowing transfection to occur during initial cell adherence. Media was replaced after $20 \mathrm{~h}$ by media containing $10 \%$ FCS (allowing cell recovery) and incubation continued for an additional $28 \mathrm{~h}$ prior to bacterial infection. Gene knock-down was confirmed by RT-PCR.

\section{Transfection of Caco-2 cells with NOD2 overexpression plasmid}

$100 \mathrm{ng}$ NOD2 expressing plasmid was transfected into Caco-2 $\left(8 \times 10^{3}\right)$ cells using FuGene reagent (Roche, Lewes, UK) as described above. For luciferase reporter gene assays, NOD2 plasmid was cotransfected with IL-8 or hBD2 promoter constructs. NOD2 expression was confirmed using RT-PCR and bacterial co-culture studies performed $48 \mathrm{~h}$ post transfection.

\section{C. jejuni invasion assay}

Caco-2 cells were plated in a 96-well plate and reversetransfected with NOD1 siRNA or overexpressing NOD2 plasmid as described above. After $48 \mathrm{~h}$ approximately $10^{7} \mathrm{cfu}$ of $C$. jejuni 81-176 cells were added to each well. Following a $20 \mathrm{~h}$ infection period, cells were incubated in media containing gentamicin $\left(150 \mu \mathrm{g} \mathrm{ml}^{-1}\right)$ for $60 \mathrm{~min}$. This procedure ensured complete kill of any adherent extracellular bacteria. Cells were washed three times with PBS prior to lysis with $0.2 \% \mathrm{v} / \mathrm{v}$ Triton X-100 (in PBS) for $15 \mathrm{~min}$ at room temperature. Serial dilutions were plated onto blood agar plates.

\section{Statistics}

Results are presented as mean \pm SE. All experiments were conducted at least three times with transfection and colonization assays performed in triplicate in each experiment. Statistical analyses were performed using GraphPad Instat statistical software, variables were compared using a $t$-test, and a probability value of $<0.05$ was regarded as significant.

\section{Acknowledgement}

This work was supported by Medical Research Council studentship (M.Z.).

\section{References}

Akira, S. (2006) TLR signaling. Curr Top Microbiol Immunol 311: 1-16.

Allos, B.M. (2001) Campylobacter jejuni infections: update on emerging issues and trends. Clin Infect Dis 32: 1201-1206.

Andersen-Nissen, E., Smith, K.D., Strobe, K.L., Barrett, S.L., Cookson, B.T., Logan, S.M., and Aderem, A. (2005) Evasion of Toll-like receptor 5 by flagellated bacteria. Proc Natl Acad Sci USA 102: 9247-9252.

Bacon, D.J., Alm, R.A., Burr, D.H., Hu, L., Kopecko, D.J., Ewing, C.P., et al. (2000) Involvement of a plasmid in virulence of Campylobacter jejuni 81-176. Infect Immun 68: 4384-4390.

Biswas, D., Itoh, K., and Sasakawa, C. (2003) Role of microfilaments and microtubules in the invasion of INT-407 cells by Campylobacter jejuni. Microbiol Immunol 47: 469473.

Black, R.E., Levine, M.M., Clements, M.L., Hughes, T.P., and Blaser, M.J. (1988) Experimental Campylobacter jejuni infection in humans. J Infect Dis 157: 472-479.

Boughan, P.K., Argent, R.H., Body-Malapel, M., Park, J.H., Ewings, K.E., Bowie, A.G., et al. (2006) Nucleotidebinding oligomerization domain-1 and epidermal growth factor receptor: critical regulators of beta-defensins during Helicobacter pylori infection. J Biol Chem 281: 1163711648.

Chamaillard, M., Hashimoto, M., Horie, Y., Masumoto, J., Qiu, S., Saab, L., et al. (2003) An essential role for NOD1 in host recognition of bacterial peptidoglycan containing diaminopimelic acid. Nat Immunol 4: 702-707.

Eckmann, L. (2005) Defence molecules in intestinal innate immunity against bacterial infections. Curr Opin Gastroenterol 21: 147-151.

Ellison, D.W., Lawrenz, M.B., and Miller, V.L. (2004) Invasin and beyond: regulation of Yersinia virulence by RovA. Trends Microbiol 12: 296-300.

Fouts, D.E., Mongodin, E.F., Mandrell, R.E., Miller, W.G., Rasko, D.A., Ravel, J., et al. (2005) Major structural differences and novel potential virulence mechanisms from the genomes of multiple campylobacter species. PLoS Biol 3: e15.

Franchi, L., McDonald, C., Kanneganti, T.D., Amer, A., and Núňez, G. (2006) Nucleotide-binding oligomerization domain-like receptors: intracellular pattern recognition molecules for pathogen detection and host defense. J Immunol 177: 3507-3513.

Fritz, J.H., Ferrero, R.L., Philpott, D.J., and Girardin, S.E. (2006) Nod-like proteins in immunity, inflammation and disease. Nat Immunol 7: 1250-1257.

Ganz, T. (2003) Defensins: antimicrobial peptides of innate immunity. Nat Rev Immunol 3: 710-720.

Girardin, S.E., Boneca, I.G., Carneiro, L.A., Antignac, A., Jehanno, M., Viala, J., et al. (2003a) Nod1 detects a unique muropeptide from gram-negative bacterial peptidoglycan. Science 300: 1584-1587. 
Girardin, S.E., Boneca, I.G., Viala, J., Chamaillard, M., Labigne, A., Thomas, G., et al. (2003b) Nod2 is a general sensor of peptidoglycan through muramyl dipeptide (MDP) detection. J Biol Chem 278: 8869-8872.

Goodyear, C.S., O'Hanlon, G.M., Plomp, J.J., Wagner, E.R., Morrison, I., Veitch, J., et al. (1999) Monoclonal antibodies raised against Guillain-Barre syndrome-associated Campylobacter jejuni lipopolysaccharides react with neuronal gangliosides and paralyze muscle-nerve preparations. J Clin Invest 104: 697-708.

Gutierrez, O., Pipaon, C., Inohara, N., Fontalba, A., Ogura, Y., Prosper, F., et al. (2002) Induction of Nod2 in myelomonocytic and intestinal epithelial cells via nuclear factor-kappa B activation. J Biol Chem 277: 41701-41705.

Hickey, T.E., Baqar, S., Bourgeois, A.L., Ewing, C.P., and Guerry, P. (1999) Campylobacter jejuni-stimulated secretion of interleukin-8 by INT407 cells. Infect Immun 67: 88-93.

Hickey, T.E., McVeigh, A.L., Scott, D.A., Michielutti, R.E., Bixby, A., Carroll, S.A., et al. (2000) Campylobacter jejuni cytolethal distending toxin mediates release of interleukin-8 from intestinal epithelial cells. Infect Immun 68: 6535-6541.

Hisamatsu, T., Suzuki, M., and Podolsky, D.K. (2003a) Interferon-gamma augments CARD4/NOD1 gene and protein expression through interferon regulatory factor- 1 in intestinal epithelial cells. J Biol Chem 278: 32962-32968.

Hisamatsu, T., Suzuki, M., Reinecker, H.C., Nadeau, W.J., McCormick, B.A., and Podolsky, D.K. (2003b) CARD15/ NOD2 functions as an antibacterial factor in human intestinal epithelial cells. Gastroenterology 124: 993-1000.

Hofreuter, D., Tsai, J., Watson, R.O., Novik, V., Altman, B., Benitez, M., et al. (2006) Unique features of a highly pathogenic Campylobacter jejuni strain. Infect Immun 74: 46944707.

Hu, L., and Hickey, T.E. (2005) Campylobacter jejuni induces secretion of proinflammatory chemokines from human intestinal epithelial cells. Infect Immun 73: 4437-4440.

Humphrey, T. (2006) Are happy chickens safer chickens? Poultry welfare and disease susceptibility. Br Poult Sci 47: 379-391.

Inohara, N., and Núňez, G. (2003) NODs: intracellular proteins involved in inflammation and apoptosis. Nat Rev Immunol 3: 371-382.

Inohara, N., Ogura, Y., and Núňez, G. (2002) Nods: a family of cytosolic proteins that regulate the host response to pathogens. Curr Opin Microbiol 5: 76-80.

Inohara, N., Chamaillard, M., McDonald, C., and Núňez, G. (2005) NOD-LRR proteins: role in host-microbial interactions and inflammatory disease. Annu Rev Biochem 74: 355-383.

Islam, D., Bandholtz, L., Nilsson, J., Wigzell, H., Christensson, B., Agerberth, B., and Gudmundsson, G. (2001) Downregulation of bactericidal peptides in enteric infections: a novel immune escape mechanism with bacterial DNA as a potential regulator. Nat Med 7: 180-185.

Janeway, C.A., Jr, and Medzhitov, R. (2002) Innate immune recognition. Annu Rev Immunol 20: 197-216.

Johanesen, P.A., and Dwinell, M.B. (2006) Flagellinindependent regulation of chemokine host defense in Campylobacter jejuni-infected intestinal epithelium. Infect Immun 74: 3437-3447.
Jones, M.A., Marston, K.L., Woodall, C.A., Maskell, D.J., Linton, D., Karlyshev, A.V., et al. (2004) Adaptation of Campylobacter jejuni NCTC11168 to high-level colonization of the avian gastrointestinal tract. Infect Immun 72: 3769-3776.

Kim, J.G., Lee, S.J., and Kagnoff, M.F. (2004) Nod1 is an essential signal transducer in intestinal epithelial cells infected with bacteria that avoid recognition by toll-like receptors. Infect Immun 72: 1487-1495.

Kobayashi, K.S., Chamaillard, M., Ogura, Y., Henegariu, O., Inohara, N., Núňez, G., and Flavell, R.A. (2005) Nod2dependent regulation of innate and adaptive immunity in the intestinal tract. Science 307: 731-734.

Konkel, M.E., and Cieplak, W., Jr (1992) Altered synthetic response of Campylobacter jejuni to cocultivation with human epithelial cells is associated with enhanced internalization. Infect Immun 60: 4945-4949.

Konkel, M.E., and Joens, L.A. (1989) Adhesion to and invasion of HEp-2 cells by Campylobacter spp. Infect Immun 57: 2984-2990.

Kopecko, D.J., Hu, L., and Zaal, K.J. (2001) Campylobacter jejuni - microtubule-dependent invasion. Trends Microbiol 9: 389-396.

Korlath, J.A., Osterholm, M.T., Judy, L.A., Forfang, J.C., and Robinson, R.A. (1985) A point-source outbreak of campylobacteriosis associated with consumption of raw milk. $J$ Infect Dis 152: 592-596.

Kufer, T.A., and Sansonetti, P.J. (2007) Sensing of bacteria: NOD a lonely job. Curr Opin Microbiol 10: 62-69.

Lambert, M.E., Schofield, P.F., Ironside, A.G., and Mandal, B.K. (1979) Campylobacter colitis. Br Med 1: 857-859.

Lamps, L.W., Schneider, E.N., Havens, J.M., Scott, M.A., Goldblum, J.R., Greenson, J.K., and Shaffer, R.A. (2006) Molecular diagnosis of Campylobacter jejuni infection in cases of focal active colitis. Am J Surg Pathol 30: 782785.

Leirisalo-Repo, M. (2005) Early arthritis and infection. Curr Opin Rheumatol 17: 433-439.

MacCallum, A., Haddock, G., and Everest, P.H. (2005) Campylobacter jejuni activates mitogen-activated protein kinases in Caco-2 cell monolayers and in vitro infected primary human colonic tissue. Microbiology 151: 27652772.

McKay, D.M., Watson, J.L., Wang, A., Caldwell, J., Prescott, D., Ceponis, P.M., et al. (2007) Phosphatidylinositol $3^{\prime}$-kinase is a critical mediator of interferon-gammainduced increases in enteric epithelial permeability. J Pharmacol Exp Ther 320: 1013-1022.

Mead, P.S., Slutsker, L., Dietz, V., McCaig, L.F., Bresee, J.S., Shapiro, C., et al. (1999) Food-related illness and death in the United States. Emerg Infect Dis 5: 607625.

Mellits, K.H., Mullen, J., Wand, M., Armbruster, G., Patel, A., Connerton, P.L., et al. (2002) Activation of the transcription factor NF-kappaB by Campylobacter jejuni. Microbiology 148: 2753-2763.

Monteville, M.R., Yoon, J.E., and Konkel, M.E. (2003) Maximal adherence and invasion of INT 407 cells by Campylobacter jejuni requires the CadF outer-membrane protein and microfilament reorganization. Microbiology 149: 153-165. 
Mooney, A., Byrne, C., Clyne, M., Johnson-Henry, K., Sherman, P., and Bourke, B. (2003) Invasion of human epithelial cells by Campylobacter upsaliensis. Cell Microbiol 5: 835-847.

Nhieu, G.T., Enninga, J., Sansonetti, P., and Grompone, G. (2005) Tyrosine kinase signaling and type III effectors orchestrating Shigella invasion. Curr Opin Microbiol 8: 16-20.

Oelschlaeger, T.A., Guerry, P., and Kopecko, D.J. (1993) Unusual microtubule-dependent endocytosis mechanisms triggered by Campylobacter jejuni and Citrobacter freundii. Proc Natl Acad Sci USA 90: 6884-6888.

Ogura, Y., Inohara, N., Benito, A., Chen, F.F., Yamaoka, S., and Núňez, G. (2001) Nod2, a Nod1/Apaf-1 family member that is restricted to monocytes and activates NF-kappaB. $J$ Biol Chem 276: 4812-4818.

Opitz, B., Puschel, A., Schmeck, B., Hocke, A.C., Rosseau, S., Hammerschmidt, S., et al. (2004) Nucleotide-binding oligomerization domain proteins are innate immune receptors for internalized Streptococcus pneumoniae. J Biol Chem 279: 36426-36432.

Park, S.F. (2002) The physiology of Campylobacter species and its relevance to their role as foodborne pathogens. Int $J$ Food Microbiol 74: 177-188.

Parkhill, J., Wren, B.W., Mungall, K., Ketley, J.M., Churcher, C., Basham, D., et al. (2000) The genome sequence of the food-borne pathogen Campylobacter jejuni reveals hypervariable sequences. Nature 403: 665-668.

Peterson, M.C. (1994) Clinical aspects of Campylobacter jejuni infections in adults. West J Med 161: 148-152.
Philpott, D.J., and Girardin, S.E. (2004) The role of Toll-like receptors and Nod proteins in bacterial infection. Mol Immunol 41: 1099-1108.

Rosenstiel, P., Fantini, M., Brautigam, K., Kuhbacher, T., Waetzig, G.H., Seegert, D., and Schreiber, S. (2003) TNFalpha and IFN-gamma regulate the expression of the NOD2 (CARD15) gene in human intestinal epithelial cells. Gastroenterology 124: 1001-1009.

Sansonetti, P.J., and Di Santo, J.P. (2007) Debugging how bacteria manipulate the immune response. Immunity 26 : 149-161.

Strober, W., Murray, P.J., Kitani, A., and Watanabe, T. (2006) Signalling pathways and molecular interactions of NOD1 and NOD2. Nat Rev Immunol 6: 9-20.

Szymanski, C.M., King, M., Haardt, M., and Armstrong, G.D. (1995) Campylobacter jejuni motility and invasion of Caco-2 cells. Infect Immun 63: 4295-4300.

Takeda, K., and Akira, S. (2005) Toll-like receptors in innate immunity. Int Immunol 17: 1-14.

Watson, R.O., and Galan, J.E. (2005) Signal transduction in Campylobacter jejuni-induced cytokine production. Cell Microbiol 7: 655-665.

Werts, C., Girardin, S.E., and Philpott, D.J. (2006) TIR, CARD and PYRIN: three domains for an antimicrobial triad. Cell Death Differ 13: 798-815.

Zilbauer, M., Dorrell, N., Boughan, P.K., Harris, A., Wren, B.W., Klein, N.J., and Bajaj-Elliott, M. (2005) Intestinal innate immunity to Campylobacter jejuni results in induction of bactericidal human beta-defensins 2 and 3 . Infect Immun 73: 7281-7289. 